\title{
STUDY ON THE WARM-COOL AND DRY-WET FEELING OF STRAW BOARD SURFACE
}

\author{
Xianging Xiong, Yiting Niu, Qingru Ma, Yuting Pan \\ Nanjing Forestry University \\ Nanjing, China \\ (Received April 20I9)
}

\begin{abstract}
To expand the application of furniture materials, the warm-cool and dry-wet tactile properties of the rice straw particleboard (RSP) surface were investigated. RSP substrates exhibiting densities equal to 757 and $554 \mathrm{~kg} \cdot \mathrm{m}^{-3}$ were sanded using different types of sandpaper (mesh 180\#, 360\#, and 600\#). Psychological experiments on sensation were then conducted by bubbling for RSP substrates. By observing and comparing changes in warm-cool and dry-wet tactile properties between the RSP and other different materials, the effects of several variables on surface tactile properties, such as sandpaper types, RSP densities, and thermal conductivities of materials, were evaluated.
\end{abstract}

KEYWORDS: Rice straw particleboard, warm-cool feeling, dry-wet feeling, surface tactile properties.

\section{INTRODUCTION}

To conform to the development trend of Made in China 2025, China has taken advantage of the great agricultural country, mitigating the shortage of materials in furniture manufacturing by straw board production ( $\mathrm{Li}$ et al. 2018, Basta et al. 2013). The rice straw particleboard (RSP) is a biomass fiber material made from the crop rice straw fiber and glued using an isocyanate adhesive (Parker 1997, Wu et al. 2019). Owing to the use of a non-aldehyde glue, it releases no free formaldehyde. In addition, the RSP is eco-friendly and exhibits uniform density and a smooth surface (Yang et al. 2003, Yan et al. 2012, Fang et al. 2019).

Warm-cool feeling and dry-wet feeling, two important characteristics of the environmental properties of wood materials, are essential criteria in the selection of furniture in the interior environment ( $\mathrm{Li}$ et al. 2019). A high or low temperature or a humid environment is not desirable. Indoor temperature and humidity should be kept within a wide comfort range (Wang et al. 2000). The RSP, a wooden artificial board, can directly improve the temperature and moisture content of the material itself, as well as our living environment, through its own functions, namely, heat 
preservation, heat insulation, moisture absorption, and dehumidification. The RSP is used as furniture or interior decoration material, improving the quality of life and work efficiency of users (Ahn et al. 2017, Shi et al. 2018).

Several studies have currently focused on the tactile properties of materials. Zhao et al. (2017) used the semantic differential technique to analyze subjective sensations when touching different materials. With this approach, the change in temperature of wood-plastic composites and other heated floor substrates is determined. The report indicated that density considerably affected the warm-cool feeling of the wood material surface and exhibited the opposite trend. That is, the higher the density, the lower the warm-cool feeling of the wood material surface. Mangat et al. (2017) measured the subjective and objective warm-cool feeling of the fabric surface after biopolishing by using human senses and Alambeta instruments. These series of studies showed that the smoothness of the fabric surface was enhanced after polishing. The smooth surface exhibited increased thermal absorption, resulting in a cool sensation when it comes in contact with a human body. Vivekanadan et al. (2011) used five methods to measure four different greige cotton denim fabrics. The fabric structure and physical properties significantly influenced the warm-cool and dry-wet feeling of the clothing surface. The finer the raw material yarn, the colder the fabric surface. The density and washing treatment also positively affected the cooling feeling of the fabric surface. Decreasing the roughness of fabric or increasing its smoothness simultaneously increase the cooling feeling of the fabric surface. Most of the research on tactile properties relate to clothing materials, and experiments on the tactile properties of the surface of wood materials, particularly research on the warm-wet feeling, are rarely reported (Goldie et al. 2001, Hu et al. 2013).

On the basis of the aforementioned reports, the current study examined the two aspects of warm-cool feeling and dry-wet feeling on the surface of RSP (Pac et al. 2001, Inoue et al. 2010, Okuyama et al. 2011, Bellizzi et al. 1992, Mangat et al. 2017). The present study employed sanding treatment with different types of sandpaper for RSPs with densities of 554 and $757 \mathrm{~kg} \cdot \mathrm{m}^{-3}$ to analyze the effects of density and surface roughness on the tactile properties, that is, warm-cool feeling and dry-wet feeling of the RSP surface. The experiment was expected to identify materials suitable for a given temperature and humidity and to determine how to improve the warm-cool feeling and dry-wet feeling of material surfaces. This study aimed to provide a broader range of materials for furniture production.

\section{MATERIALS AND METHODS}

\section{Materials}

RSPs were purchased from Novofibre Co., Ltd. (Yangling, Shanxi, China). The two RSP plates with different densities varied in performance. The density of the first plate was $554 \mathrm{~kg} \cdot \mathrm{m}^{-3}$, and the moisture content was $8.0 \%$. The density of the second plate was $757 \mathrm{~kg} \cdot \mathrm{m}^{-3}$, and the moisture content was 7.5\%. Experimental specimens measuring $200 \times 200 \times 10 \mathrm{~mm}$ were taken from these two RSP plates with different densities, resulting in 12 specimens with a density of $554 \mathrm{~kg} \cdot \mathrm{m}^{-3}$, and 10 specimens with a density of $757 \mathrm{~kg} \cdot \mathrm{m}^{-3}$ for a total of 22 specimens. Other experimental specimens $300 \times 200 \times 10 \mathrm{~mm}$ (including poplar medium density particleboard (PB), foam plastic, pine board, and marble) and four pieces were taken. Other auxiliary materials included sanding materials, absorbent papers, fresh-keeping bags, sinks, and homemade metal grid, among others. 


\section{Experimental apparatus}

A stainless steel probe-type electronic thermometer was purchased from Hengxing Instrument Co., Ltd. (Hengshui, Hebei, China). This instrument had a measurement accuracy of $0.01^{\circ} \mathrm{C}$, a temperature measurement range of $-50^{\circ} \mathrm{C}$ to $300^{\circ} \mathrm{C}$, and a measurement time of $60 \mathrm{~s}$ (Shen and Lv 2018).

An electronic scale was supplied by Shanghai Yousheng Electronic Weighing Apparatus Co. (Shanghai, China) with a measurement accuracy of $0.01 \mathrm{~g}$ and a measurement range of 0-600 g.

\section{Experiment method}

Grouping of specimens and preparation

The prepared specimens were divided into three groups (labeled as MSB-A, MSB-B, and MSB-C), and each group consisted of two specimens. MSB-A and MSB-C had a density of $554 \mathrm{~kg} \cdot \mathrm{m}^{-3}$, and MSB-B had a density of $757 \mathrm{~kg} \cdot \mathrm{m}^{-3}$.

In addition, two groups of RSPs with different densities were divided into Groups A and B (Tab. 1). Each specimen was further divided into four pieces and then grouped based on the difference in sandpaper and sanding time. Group A had a density of $554 \mathrm{~kg} \cdot \mathrm{m}^{-3}$, and Group B had a density of $757 \mathrm{~kg} \cdot \mathrm{m}^{-3}$, each test was repeated twice. A1-A4 (four groups) and B1-B4 (four groups) were used for numbering groups and marking the back of the specimens. A1 and B1 specimens comprised the control group, representing the specimens that were not subjected to sand treatment.

Tab. 1: Group number and treatment of specimens.

\begin{tabular}{|c|c|c|c|}
\hline $\begin{array}{c}\text { Group } \\
\text { number }\end{array}$ & $\begin{array}{c}\text { Density of RSP } \\
\left(\mathrm{kg} \cdot \mathrm{m}^{-3}\right)\end{array}$ & $\begin{array}{c}\text { Sandpaper } \\
\text { models/\# }\end{array}$ & $\begin{array}{c}\text { Sanding time } \\
(\mathrm{min})\end{array}$ \\
\hline A1 & 554 & 0\# (Untreated) & 0 \\
\hline A2 & 554 & $180 \#$ & 2 \\
\hline A3 & 554 & $360 \#$ & 2 \\
\hline A4 & 554 & $600 \#$ & 2 \\
\hline B1 & 757 & 0\# (Untreated) & 0 \\
\hline B2 & 757 & $180 \#$ & 2 \\
\hline B4 & 757 & $600 \#$ & 2 \\
\hline
\end{tabular}

\section{Experiment on interface temperature and humidity}

Three groups (MSB-A, MSB-B, and MSB-C) of RSP specimens were marked and sanded with 180\# sandpaper. The MSB-A and MSB-B specimens were sanded for $1 \mathrm{~min}$, and the MSB-C specimens were sanded for 2 min. The principle of grain sanding was applied, and sanding time was controlled with a stopwatch to ensure the accuracy of the experiment (Xiong et al. 2015, Molnar et al. 2017, Magoss et al. 2019). Except for the RSP specimens, all specimens (including PB, foam plastic, pine board, and marble) were not sanded. Hands were placed on the surface of the different materials to be tested. The temperature between the palm of the test subject and the interface of the specimen was measured using an electronic thermometer, and the results were recorded. Contact duration were set to $0,10,20,30$, and $40 \mathrm{~s}$.

First, two RSPs with different densities (from MSB-A and MSB-B) were sanded with sandpaper of different models (180\#, 360\#, 600\#) for 2 min. The treated specimens were then kept in a room-temperature environment after $24 \mathrm{~h}$ until a weight difference of $0.1 \%$ between the specimens was achieved. Subsequently, the constant specimens were weighed, and the value obtained was recorded as the quality before immersion. The specimens were fixed with a metal 
grid, immersed in warm water with $\mathrm{pH}$ of almost 7 for $24 \mathrm{~h}$, and taken out. The surfaces were subsequently wiped and then placed in a fresh-keeping bag. The weights were determined and then recorded as the quality after immersion. The $24 \mathrm{~h}$ water absorption rate of the specimens was calculated based on their quality before and after immersion.

\section{Experiment on psychological quantity}

In the case in which the experimental subjects were blindfolded, the tactile psychological quantity of the treated specimens was measured. The specimens, which were randomly placed on the top of a table, were touched in a uniform grain direction. The MSB-A and MSB-B specimens and other materials were sorted based on their degree of coldness and warmth by using the bubble method. Two adjacent test specimens were compared with respect to the coldness and warmth of the surface, and the warmer surface was placed in front. The comparison continued for the remaining specimens until the order of last specimens. In accordance with the order after sorting, the experimental subjects recorded the position of each specimen and rated the specimens as follows: +4 , warmest; +2 , warmer; 0 , warm; -2 , cool; -4 , cooler; and -6 , coolest. Scores were subsequently assigned. The average of each group was determined, and the value obtained was considered as the final tactile psychological quantity in the warm-cool feeling experiment. The specimens were observed from $0.5 \mathrm{~m}$ by the experimental subjects with the naked eye. With reference to the testing method used to determine the tactile psychological quantity, the degrees of coldness and warmth of the specimen were assessed, and the average was assigned as the final visual psychological quantity of the specimen.

Under the same method (from dry to wet), the specimens were rated as follows: +3 , driest; +2 , drier; +1 , dry; 0 , generally; -1 , wet; -2 , wetter; and -3 , wettest. Two specimens from Groups $\mathrm{A}$ and $\mathrm{B}$ and other materials were subsequently assigned scores. The average for each group was ultimately assigned as the final tactile and visual psychological quantities in the dry-wet feeling experiment.

\section{RESULTS AND DISCUSSION}

\section{Warm-cool feeling experiment}

After the sanding treatment, the temperature of specimens was recorded by the above measurement method, and each specimen was tested three times and the average value of the three test results were taken as the final evaluation parameter (Tab. 2). Through the touch of RSP and other materials, as well as the observation of naked eyes, the degree of warm-cool feeling was tested and recorded according to the grading standard, and the averages were taken as the final tactile and visual psychological quantities in the warm-cool feeling experiment (Tab. 3).

Tab. 2: Surface temperature of different specimens under different sanding treatments.

\begin{tabular}{|c|c|c|c|c|c|c|c|}
\hline \multirow{2}{*}{$\begin{array}{c}\text { Contact } \\
\text { duration (s) }\end{array}$} & \multicolumn{7}{|c|}{ Surface temperature $\left({ }^{\circ} \mathrm{C}\right)$} \\
\hline 0 & MSB-A & MSB-B & MSB-C & PB & Foam plastic & Pine board & Marble \\
\hline 10 & 34.21 & 34.21 & 34.21 & 34.21 & 34.21 & 34.21 & 34.21 \\
\hline 20 & 32.65 & 33.25 & 33.42 & 33.35 & 33.85 & 33.68 & 32.53 \\
\hline 30 & 32.30 & 32.53 & 32.61 & 32.68 & 33.25 & 32.84 & 31.55 \\
\hline 40 & 32.08 & 31.83 & 32.20 & 32.15 & 33.04 & 32.65 & 31.05 \\
\hline
\end{tabular}


Vol. 65 (2): 2020

Tab. 3: Tactile and visual psychological quantities of different specimens in the warm-cool feeling experiment.

\begin{tabular}{|l|c|c|}
\hline \multicolumn{1}{|c|}{ Specimen } & Tactile psychological quantity & Visual psychological quantity \\
\hline MSB-A & +0.1 & +1.5 \\
\hline MSB-B & -3.2 & -2.0 \\
\hline PB & -2.8 & -4.0 \\
\hline Foam plastic & +4.0 & +4.0 \\
\hline Pine board & +1.9 & +0.5 \\
\hline Marble & -6.0 & -6.0 \\
\hline
\end{tabular}

The effects of variations in density and roughness on the surface temperature of the RSP specimens are presented in Figs. 1 and 2. The effects on the tactile and visual psychological quantities of the RSP specimens are shown in Fig. 3.

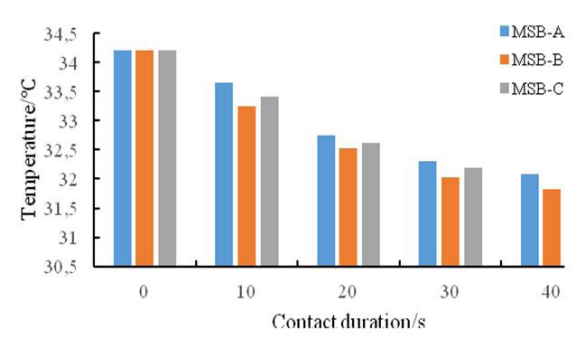

Fig. 1: Surface temperature of RSP specimens with different contact duration.

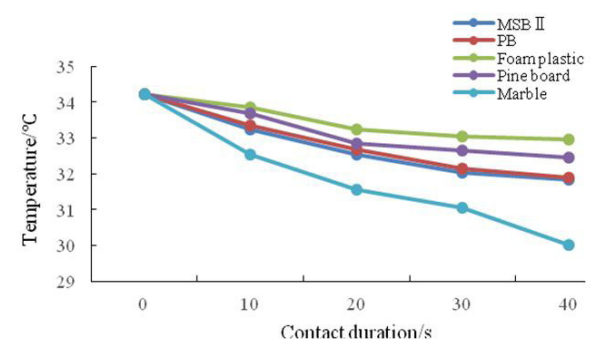

Fig. 2: Surface temperatures of different materials with different duration.

(1) The temperatures of the palms of the experimental subjects decreased continuously as contact duration with RSP increased (Fig. 1). The maximum change occurred at contact duration with $10 \mathrm{~s}$, which tended to stabilize after $30 \mathrm{~s}$. Roughness exerted an effect to a certain extent, but such was not evident in the warm-cool feeling of the RSP surface. With an increase in sanding time, the roughness of the RSP surface decreased and the warmth increased. At a constant surface roughness, the temperatures of the specimens with a lower density (MSB-A) were always higher than those of the specimens with a higher density (MSB-B). That is, density exerted a more significant influence on the warm-cool feeling of the RSP surface. The higher the density, the cooler the RSP surface. By consulting the literature, it can be seen that Zhao et al. (2017) also concluded that the density was negatively correlated with the surface temperature of the substrates when they study and compare the temperature changes between wood-plastic composites and other heated floor substrates. The same trend exists in related research in different fields, especially the research on the warm-cool feeling of the fabric surface in garment industry. Zhang (2016) of Donghua University has analyzed that the density of fabric has a significant effect on its surface warm-cool feeling by establishing a physical model of the temperature between the fingertip and the fabric, the greater the density, the lower the temperature of fabric surface. Zhang et al. (2017) has tested the warm-cool feeling of 14 different fabrics by a precision instantaneous thermal property tester. The experimental results showed that the smoothness and density had the opposite tendency to the warm-cool feeling of fabric surface. 
In Fig. 2, the temperature curve of PB basically coincided with that of the RSP (MSB-B), indicating that the two materials exhibited a similar warm-cool feeling. RSPs had a similar warm-cool feeling as that of the particle board made of other types of wood. In several wood materials, the surface of pine exhibited the lowest change in warm-cool feeling. This finding was mainly attributed to its high internal porosity and low thermal conductivity, which resulted in a lower temperature change between pine and human contact interface than that between other artificial panels and human contact interface. The temperature change in marble was the largest. The highest thermal conductivity of the marble suggested that the marble was not suitable for use in furniture materials, which often are in contact with the human body. Foam plastic exhibited the strongest warm-cool feeling and the highest contact-interface temperature. The temperature change was considerably affected by the environment. Long-term contact affects comfort.

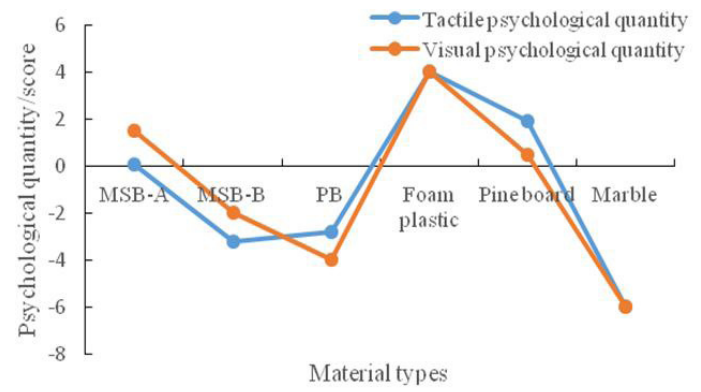

Fig. 3: Psychological quantity of different materials in a warm-cool feeling experiment.

(2) The psychological quantity of the RSP specimens and other wood specimens was between that of the marble and that of the foam plastic (Fig. 3), indicating compared with the RSP specimens, wood materials provided greater comfort as furniture materials. Compared with that of the artificial panel, the pine specimens had a lower density and a softer texture. Therefore, the tactile psychological quantity of pine specimens was higher than those of the RSP and PB specimens. Density significantly influenced the tactile psychological quantity of the RSP specimens. When the sanding time of MSB-A and MSB-B were similar, the MSB-B surface exhibited cooler tactile and visual psychological quantities. The tactile warmth of the RSP specimens was lower than that of $\mathrm{PB}$. The reason was that PB and solid wood exhibited a similar texture, with $\mathrm{PB}$ achieving increased tactile warmth after a layer of veneer treatment. With respect to the visual psychological quantity, the surface of the MSB-B specimens exhibited a certain roughness after the sanding treatment. The RSP fiber induced diffused reflection on the surface; in addition, the PB surface was varnished and not sanded in the experiment. Consequently, the PB surface was smoother, and their refractive index was higher, thereby decreasing their visual psychological quantity and cooler tactile quality.

\section{Dry-wet feeling experiment}

The $24 \mathrm{~h}$ absorption rate was calculated by recording the quality before and after immersion of the specimens, and each specimen was tested three times and the averages of the three test results were taken as the final evaluation parameter (Tab. 4). Through the touch of RSP and other materials, as well as the observation of naked eyes, the degree of dry-wet feeling was tested and recorded according to the grading standard, and the averages were taken as the final tactile and visual psychological quantities in the dry-wet feeling experiment (Tab. 5). 
Tab. 4: 24 h water absorption rate of RSP specimens.

\begin{tabular}{|c|c|c|c|}
\hline Group number & $\begin{array}{c}\text { Quality before } \\
\text { immersion (g) }\end{array}$ & $\begin{array}{c}\text { Quality after } \\
\text { immersion (g) }\end{array}$ & $\begin{array}{c}24 \text { h water } \\
\text { absorption rate (\%) }\end{array}$ \\
\hline A1 & 32.05 & 48.27 & 50.6 \\
\hline A2 & 32.14 & 46.59 & 44.96 \\
\hline A3 & 30.12 & 44.5 & 44.77 \\
\hline A4 & 32.93 & 47.5 & 44.25 \\
\hline B1 & 33.46 & 43.65 & 30.45 \\
\hline B2 & 37.35 & 48.07 & 28.7 \\
\hline B3 & 35.31 & 45.82 & 28.23 \\
\hline B4 & 35.84 & 45.84 & 27.9 \\
\hline
\end{tabular}

Tab. 5: Tactile and visual psychological quantities of different specimens in the dry-wet feeling experiment.

\begin{tabular}{|l|c|c|}
\hline Specimen number & Tactile psychological quantity & Visual psychological quantity \\
\hline MSB-A & 1.8 & +1.5 \\
\hline MSB-B & -2.1 & -1.9 \\
\hline MSB-C & +0.1 & +0.2 \\
\hline PB & -2.1 & -1.5 \\
\hline Foam plastic & +3.0 & +3.0 \\
\hline Pine board & +1.9 & +1.7 \\
\hline Marble & -3.0 & -3.0 \\
\hline
\end{tabular}

The effects of variations in density and surface roughness on the $24 \mathrm{~h}$ water absorption rate of the RSP are presented in Fig. 4. The effects on the tactile and visual psychological quantities are shown in Fig. 5.

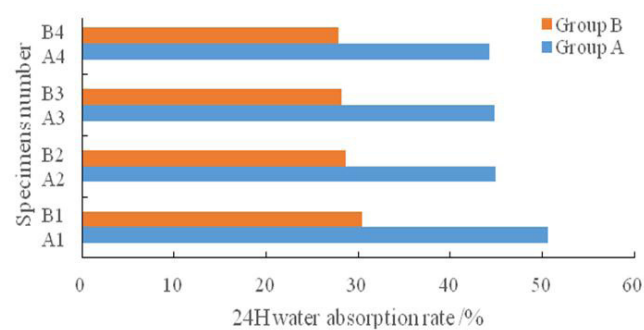

Fig. 4: $24 \mathrm{~h}$ water absorption rates of different materials.

(1) Density significantly affected the water absorption performance of the specimens (Fig. 4). Considerable difference in water absorption was found between Groups A and B. The lowest water absorption rate of the specimens in Group A was $44.25 \%$, which was far greater than the highest absorption rate of the specimens in Group B. This finding indicated that the higher the density of the RSP, the poorer the water absorption. The RSP with a greater density had a smaller gap between the fibers, thereby decreasing water absorption. By consulting the literature, we can see that there is a similar relationship between the density and absorption rate in garment industry. Shen (2007) of Xi'an polytechnic university has analyzed that as the density and thickness of the fabric increased, the water absorption ability of the fabric showed 
a decreasing trend. Compared with density, the surface roughness affected the water absorption of RSP, but the effect was not apparent. The specific effects exhibited a proportional tendency, and the lower the surface roughness, the poorer the water absorption.

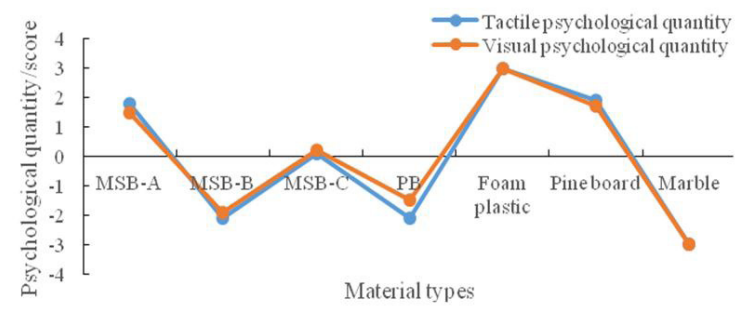

Fig. 5: Psychological quantity of different materials in the dry-wet feeling experiment.

(2) The tactile and visual psychological quantities of wood materials were between that of the marble and that of the foam plastic (Fig. 5). This finding indicates that wood materials had a good dry-wet tactile quality. Contact between the human body and the material could produce tactile and visual comfort. Therefore, wood materials could be used widely in furniture materials. The higher the density, the lower the tactile and visual psychological quantities of the RSP specimens, thus providing humidity to human bodies. With density remaining the same, the higher the surface roughness of the specimen, the drier the surface. The dry-wet feeling of the RSP surface could be improved by veneering, and the comfortable feeling as furniture materials increased. Among the three materials, PB achieved the lowest psychological and visual psychological quantities. The reason is that the surface of $\mathrm{PB}$ were treated with veneer and then finished, thus increasing the smoothness of the panel surface. The surface had a poor dry-wet feeling relative to that of the solid wood board.

\section{CONCLUSIONS}

(1) After the RSP specimens with two different densities were sanded using different types of sandpaper and sanding time, the surface tactile properties were evaluated by conducting warm-cool feeling and dry-wet feeling experiments. Density and roughness significantly affected the tactile properties of RSP, and the influence of density is greater than that of the surface.

(2) The surface tactile properties of the RSP are closest to those of the poplar mediumdensity particleboard. However, the RSP has a preferable water absorption for adjusting indoor humidity.

(3) Among the several materials tested, the solid wood materials exhibited the highest tactile and visual psychological quantities. This superior characteristic is also the reason solid wood is most widely used in furniture and interior decoration.

\section{ACKNOWLEDGEMENTS}

The authors are grateful for Natural Science Foundation of Jiangsu Province (CN) (No. BK20150881). 


\section{REFERENCES}

1. Ahn, E., Yeom, D., Lee, K.I., 2017: Experimental research on the indoor environment performance of complex natural insulation material: carbonized rice hull and rice hull. Journal of Asian Architecture and Building Engineering 16(1): 239-246.

2. Basta, A.H., Lotfy, V.F., 2013: Performance of rice straw-based composites using environmentally friendly polyalcoholic polymers-based adhesive system. Pigment \& Resin Technology 42(1): 24-33.

3. Bellizzi, J. A., Hite, R. E., 1992: Environmental color, consumer feelings, and purchase likelihood. Psychology \& marketing 9(5): 347-363.

4. Fang, L., Zeng, J., Liao, X., Zou, Y., Shen, J., 2019: Tensile shear strength and microscopic characterization of veneer bonding interface with polyethylene film as adhesive. Science of Advanced Materials 9: 1223-1231.

5. Goldie, L., Weedall, P.J., 2001: The objective measurement of the 'cool feeling' in fabrics. The Journal of the Textile Institute, Part 3. Technologies for a New Century 92(4): 379-386.

6. Hu, S. R., Li, J., 2013: Study on warm-cool feeling of knitted fabric. Advanced Materials Research 2735(1643): 309-312.

7. Inoue, T., Nakayama, A., Niwa, M., 2010: Relationship between the warm/cool feeling of fabric and the subjective evaluation of the quality of ladies' knitted fabrics. International journal of clothing science and technology 22(1): 7-15.

8. Li, R., Xu, W., Wang, X., Wang, C., 2018: Modeling and predicting of the color changes of wood surface during $\mathrm{CO}_{2}$ laser modification. Journal of cleaner production 183: 818-823.

9. Li, Q. Jiang, H., Tang, Q. Chen, Y., Li, J., Jian, Z., 2018: Smart manufacturing standardization: reference model and standards framework. Computer Integrated Manufacturing Systems 101: 91-106.

10. Magoss, E., Molnár, Z., Suri, V., 2019: Evaluating of wetting-induced effects on the surface stability of sanded wood. Wood Research 64(3): 401-410.

11. Mangat, A., Hes, L., Bajzik, V., 2017: Effect of biopolishing on warm-cool feeling of knitted fabric: a subjective and an objective evaluation. Autex Research Journal 17(2): 95-102.

12. Molnár, Z., Németh, G., Sandor, Héjja, S., Magoss, E., Tatai, S., 2017: The effect of the position of $2 \mathrm{D}$ roughness measurement on the roughness parameters by natural wood material. Wood Research 62(6): 895-903.

13. Okuyama, T., Hariu, M., Kawasoe, T., Kakizawa, M., Shimizu, H., Tanaka, M., 2011: Development of tactile sensor for measuring hair touch feeling. Microsystem technologies 17(5-7): 1153-1160.

14. Pac, M. J., Bueno, M. A., Renner, M., E1 Kasmi, S. 2001: Warm-cool feeling relative to tribological properties of fabrics. Textile Research Journal 71(9): 806-812.

15. Parker, P., 1997: A summary report on building materials produced from wheat straw. Inorganic Bonded Wood Fiber Composite Material 5: 47-48.

16. Shen, H., Lv, G., 2018: Calibration Method for surface thermometer. Metrology \& Measurement technology 1: 93-95.

17. Shen, L., Fan, L., Zhang, L., 2007: Test analyses of heat and moisture property of bamboo fiber fabric. Cotton Textile Technology 35(5): 1-4.

18. Shi, L., Zhang, H., Li, Z., Man, X., Wu, Y., Zheng, C., Liu, J., 2018: Analysis of moisture buffering effect of straw-based board in civil defence shelters by field measurements and numerical simulations. Building and Environment 143: 366-377. 
19. Vivekanadan, M.V., Raj, S., Sreenivasan, S., Nachane, R.P., 2011: Parameters affecting warm-cool feeling in cotton denim fabrics. Computers \& Geosciences 36(2): 117-121.

20. Wang, S., Lin, F., Lin, M., 2000: Thermal properties of interior decorative material and contacted sensory cold-warmth 1: relation between skin temperature and contacted sensory cold-warmth. Journal of Wood Science 46(5): 357-363.

21. Wu Y., Bian Y., Yang F., Ding Y., Chen K., 2019: Preparation and properties of chitosan/ graphene modified bamboo fiber fabrics. Polymers 11: 1540.

22. Xiong, X., Jiang, Y., Xu, W., 2015: The Roughness tactile properties of the straw board surface. Packing Engineering 36(3): 42-47.

23. Yan, Y., Li, X., Liu, X., 2012: Study on hot-pressing process of straw particle board. Journal of Central South University of Forestry \& Technology 32(1): 126-129.

24. Yang, H. S., Kim, D. J., Kim, H. J., 2003: Rice straw-wood particle composite for sound absorbing wooden construction materials. Bioresource Technology 86(2): 117-121.

25. Yi, X., Zhao, D., Ou, R., Ma, J., Chen, Y., Wang, Q. 2017: A comparative study of the performance of wood-plastic composites and typical substrates as heating floor. Bioresources 12(2): 2565-2578.

26. Zhang, W., 2016: Study on computer modelling of fabric contact thermal sensation. Donghua University, Shanghai, China, pp. 5-15.

27. Zhang, X., Wang, L., Chen, Y., 2017: Formation mechanism and influence factors of warm-cool feeling of knitted underwear fabrics. Journal of Textile Research 38(1): 57-60.

\author{
Xianeing Xiong ${ }^{1,2^{*}}$, Yiting $\mathrm{NiU}^{1,2}$, Qingru MA ${ }^{1,2}$, Yuting Pan ${ }^{1,2}$ \\ Nanjing Forestry University \\ ${ }^{1}$ Co-Innovation Center of Efficient Processing and Utilization of Forest \\ Resources \\ ${ }^{2}$ College of Furnishings and Industrial Design \\ Nanjing Forestry University \\ NANJING 210037 \\ China \\ *Corresponding author: xiongxianqing@njfu.edu.cn
}

